\title{
Computed Tomography of Lymph Node Metastasis Before and After Radiation Therapy: Correlations With Residual Tumour
}

\author{
NAOYA ISHIBASHI ${ }^{1}$, TOSHIYA MAEBAYASHI $^{1}$, HARUNA NISHIMAKI ${ }^{2}$ and MASAHIRO OKADA ${ }^{1}$ \\ ${ }^{1}$ Department of Radiology, Nihon University School of Medicine, Tokyo, Japan; \\ ${ }^{2}$ Department of Oncologic Pathology, Nihon University School of Medicine, Tokyo, Japan
}

\begin{abstract}
Background: Computed tomography (CT) performed after radiation therapy $(R T)$ is used to detect residual lymph node (LN) metastasis. Here, we investigated which LN parameters on pre- and post-RT CT images correlated with residual tumour in patients with head and neck cancer. Patients and Methods: We enrolled 23 patients who received RT. A total of 50 LNs were evaluated. Correlations between quantitative and qualitative findings and residual tumours were evaluated. Results: The median patient age was 61 years. Thirty-one LNs were histologically confirmed to contain residual tumour. LNs with residual tumour had significantly longer short and long axes on postRT CT images. A new finding of obscured margins after RT were significantly associated with the presence of residual tumour by univariate and multivariate analyses. Conclusion: Comparison of qualitative, LN parameters on pre- and postRT CT images may improve the detection of residual tumour in patients with suspected residual or recurrent $L N$ metastasis.
\end{abstract}

Radiation therapy (RT) is often selected for the treatment of head and neck cancer with the goal of preserving function. Salvage neck dissection (ND) can also be considered as standard of care for residual or recurrent neck lymph node (LN) metastasis after RT $(1,2)$. In a phase III randomised trial of 271 patients, salvage ND was included in the treatment protocol for residual neck $\mathrm{LN}$ metastasis detected

This article is freely accessible online.

Correspondence to: Dr. Naoya Ishibashi, Department of Radiology, Nihon University School of Medicine, 30-1, Oyaguchi Kami-cho, Itabashi-ku, Tokyo 173-8610, Japan. Tel: +81 339728111, Fax: +81 339582454, e-mail: ishibashi.naoya@nihon-u.ac.jp

Key Words: Computed tomography, head and neck cancer, histopathology, lymph node metastasis. during an interim assessment of RT response (3). However, it is extremely difficult to determine using imaging whether a neck LN metastasis after RT has a residual tumour because of oedema and inflammation in the surrounding tissues. One study reported that as many as $87.5 \%$ of patients diagnosed with residual tumours after RT by imaging did not have tumours on pathological examination of salvage ND specimens (4). Many previous studies have compared only the reduction in the size of neck LNs after $\mathrm{RT}$, as evaluated by computed tomography (CT), with the histopathological findings of salvage ND specimens (4-7). In the present study, we aimed to investigate which tumour parameters on imaging best correlated with the presence or absence of residual tumour in patients with head and neck cancer. To this end, we evaluated changes in CT findings of neck LN metastases before and after RT, assessing not only the size but also various qualitative parameters, and compared them with the histopathological results of salvage ND specimens.

\section{Patients and Methods}

Patients and specimens. A total of 23 patients with biopsyconfirmed head and neck cancer were included in the study. RT was initiated between May 2010 and December 2018, and CT was performed before and after completion of RT. During salvage ND, we removed and examined a total of $50 \mathrm{LNs}$ that were classified as suspicious for residual or recurrent neck metastasis by CT after RT.

This study was retrospective and informed consent was obtained from all patients and the study was performed in accordance with the Declaration of Helsinki.

Evaluation of lymph nodes by CT before and after RT. LNs were evaluated before RT on axial images of contrast-enhanced CT with a slice thickness of $\leq 5 \mathrm{~mm}$ using the Synapse Picture Archiving and Communication System viewer (Fuji Medical Systems, Tokyo, Japan). Suspected metastases were defined as the presence of (i) target LNs with a short axis of $\geq 15 \mathrm{~mm}$ according to the Response Evaluation Criteria in Solid Tumors (8), (ii) LNs with a long-toshort axis ratio of $<2$ according to previous reports (9), or (iii) 
presence of internal features such as necrosis, cystic lesion, and extracapsular spread (9-11). The diagnosis was made by experienced radiologists. After RT, size measurements on neck LNs suspicious for residual or recurrent metastasis (i.e. short axis, long axis, and long-to-short axis ratio) were evaluated on CT images taken before ND. For LNs with metastasis suspected before RT, the size was measured before and after RT. In addition, the same radiologists diagnosed the presence of changes after RT that were not observed before RT, such as obscuration of the margins, internal necrosis, calcification, and strong contrast enhancement.

Radiation therapy. All patients were treated with three-dimensional conformal RT with 4-MV photon beams. The initial radiation field included not only the gross tumour volume of the primary site but also the involved or regional LN levels. The radiation dose was 2 Gy per fraction per day. A radical radiation dose of 66 Gy was administered to 20 patients. Two patients received a total preoperative radiation dose of $40 \mathrm{~Gy}$. In one patient, the therapeutic strategy was changed to surgery because of insufficient response to RT after a total dose of $26 \mathrm{~Gy}$.

Concurrent chemotherapy regimens. The most common regimen of systemic chemotherapy administered in combination with RT was docetaxel, cisplatin, and 5-fluorouracil in 14 patients $(60.9 \%)$, followed by cisplatin alone (13.0\%), cetuximab alone (13.0\%), and a docetaxel-based regimen (13.0\%) in three patients each.

Comparison of lymph nodes by histopathology and imaging. Surgical photographs and histology sections of excised LNs were reviewed by experienced pathologists and compared with $\mathrm{CT}$ images. The radiologists and pathologists ensured that the LNs evaluated radiographically and histopathologically were the same.

Statistical analysis. SPSS version 21.0 (IBM, Armonk, NY, USA) was used for statistical analysis. Univariate analysis with the MannWhitney $U$-test was performed to evaluate associations between $\mathrm{LN}$ size measured on CT images pre- and post-RT and histopathologically confirmed residual tumours after ND. Associations between size reduction (relative to the median) or new changes after RT and histopathologically confirmed residual tumours after ND were evaluated by univariate analysis with Pearson's chi-squared test and by multivariate analysis with simultaneous logistic regression. A $p$-value of less than 0.05 was considered statistically significant.

\section{Results}

Clinicopathological characteristics. The characteristics of the 23 patients are summarised in Table I. A total of 21 men and two women were included, and the median age at the start of RT was 61 (range $=47$ to 72 ) years. The most common primary tumour site was the oropharynx, followed by the hypopharynx. Primary tumour pathology included squamous cell carcinoma in 21 patients, malignant neoplasm only in one patient, and carcinoma with neuroendocrine differentiation in one patient. Post-RT CT of LNs with suspected residual or recurrent metastasis was performed at a median of 45 (range $=1$ to 664 ) days after completion of
Table I. Clinicopathological characteristics of the patients.

\begin{tabular}{|c|c|c|}
\hline Variable & & Value \\
\hline \multirow[t]{3}{*}{ Age, years } & Median (range) & $61(47-72)$ \\
\hline & Male & $21(91.3 \%)$ \\
\hline & Female & $2(8.7 \%)$ \\
\hline \multirow{6}{*}{$\begin{array}{l}\text { Primary tumour } \\
\text { site }\end{array}$} & Nasopharynx & $2(8.7 \%)$ \\
\hline & Oropharynx & $9(39.1 \%)$ \\
\hline & Hypopharynx & $7(30.4 \%)$ \\
\hline & Larynx & $2(8.7 \%)$ \\
\hline & Oral cavity & $2(8.7 \%)$ \\
\hline & Unknown & $1(4.4 \%)$ \\
\hline \multirow{4}{*}{$\begin{array}{l}\text { Chemotherapy } \\
\text { regimen }\end{array}$} & $\mathrm{TPF}$ & $14(60.9 \%)$ \\
\hline & Cisplatin only & $3(13.0 \%)$ \\
\hline & Cetuximab only & $3(13.0 \%)$ \\
\hline & Docetaxel-based & $3(13.0 \%)$ \\
\hline \multirow[t]{6}{*}{$\begin{array}{l}\text { New changes } \\
\text { in LN after RT* }\end{array}$} & $\begin{array}{l}\text { Median reduction, } \\
\text { short axis (range), } \mathrm{mm}\end{array}$ & $5.05(-15.8-15.8)$ \\
\hline & $\begin{array}{l}\text { Median reduction, } \\
\text { long axis (range), } \mathrm{mm}\end{array}$ & $5.75(-17.1-28.3)$ \\
\hline & Obscuration of the margins & $8(16.0 \%)$ \\
\hline & Internal necrosis & $10(20.0 \%)$ \\
\hline & Calcification & $8(16.0 \%)$ \\
\hline & Strong contrast enhancement & $6(12.0 \%)$ \\
\hline \multirow{2}{*}{$\begin{array}{l}\text { Histopathological } \\
\text { residual tumor } \\
\text { in } \mathrm{LN}^{*}\end{array}$} & Yes & $19(38.0 \%)$ \\
\hline & No & $31(62.0 \%)$ \\
\hline
\end{tabular}

TPF: Docetaxel, cisplatin, and 5-fluorouracil; LN: lymph node; RT: radiation therapy $*$ Percentage of the $50 \mathrm{LNs}$ collected.

RT. Histopathological examination of the 50 ND specimens revealed $19 \mathrm{LNs}$ with residual tumour.

Lymph node size. In the LNs without histopathologically confirmed residual tumour, the median short and long axes on CT images before RT were 15.2 (range=7.1 to 38.1 ) $\mathrm{mm}$ and 19.4 (range $=8.6$ to 56.6 ) $\mathrm{mm}$, respectively, with a longto-short axis ratio of 1.32 (range $=1.01$ to 1.75 ). In the same LNs, the median short and long axes on CT images after RT (performed before ND) were 6.5 (range $=3.0$ to 49.1 ) $\mathrm{mm}$ and 10.0 (range=to 5.1 to 57.5 ), respectively, with a long-to-short axis ratio of 1.42 (range $=1.01$ to 2.65$) \mathrm{mm}$.

In the LNs with histopathologically confirmed residual tumour, the median short and long axes before RT were 10.8 (range $=7.6$ to 31.1 ) $\mathrm{mm}$ and 14.7 (range=9.0 to 41.6 ) $\mathrm{mm}$, respectively, with a long-to-short axis ratio of 1.34 (range $=1.03$ to 1.74 ) In the same LNs, the median short and long axes after RT (before ND) were $11.6 \mathrm{~mm}$ (range $=4.4$ to 24.8 ) and $14.6 \mathrm{~mm}$ (range=6.0 to 30.0), respectively, with a long-to-short axis ratio of 1.32 (range $=1.00$ to 1.70 ) Taking all $50 \mathrm{LNs}$ together, the median size reduction after RT was $5.05 \mathrm{~mm}$ (range=-15.8-15.8) for the short axis and $5.75 \mathrm{~mm}$ (range=-17.1-28.3) for the long axis (Table I). 


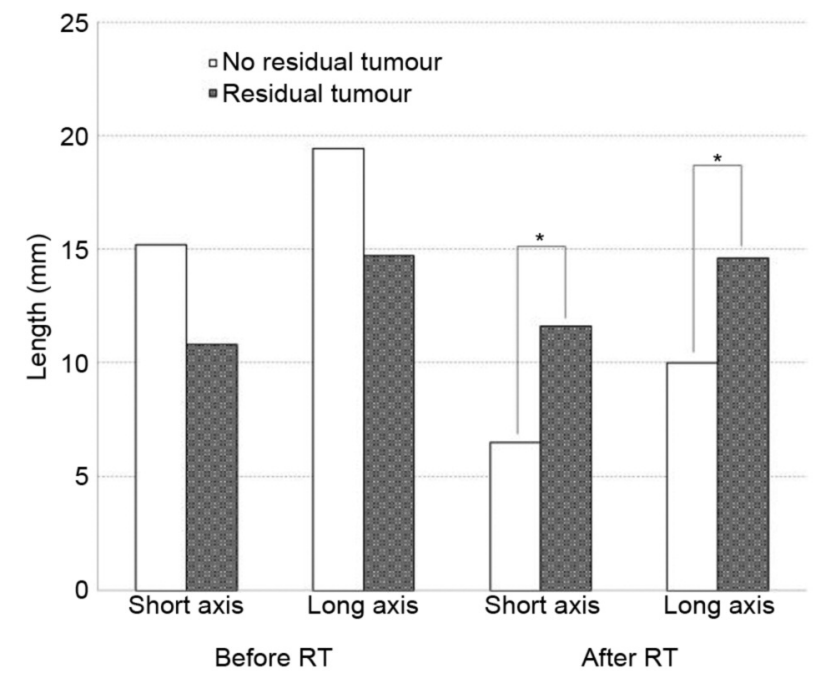

Figure 1. Lymph node size comparison between patients. Lymph node sizes were compared between patients with and without residual tumour before and after radiation therapy $(R T)$. *Significantly different at $p=0.007$ (short axis) and $p=0.022$ (long axis).

The short and long axes of LNs measured after RT were significantly longer for LNs with residual tumour compared with those without residual tumour (Figure 1). However, there were no significant associations between the pre-RT axis lengths or axis ratio and the presence of residual tumours.

New changes in LNs detected after RT. Univariate analysis showed that residual tumours were found significantly more often in LNs with a poor response to RT (i.e.<median size reduction for long and short axes) and in those with obscured margins after RT (Table II). However, only the association between residual tumour and obscuration of the margins remained significant by multivariate analysis (Figure 2 and Table II). There were no significant correlations between the other new changes after RT (internal necrosis, calcification, strong contrast enhancement) and the presence of residual tumours.

\section{Discussion}

Numerous studies have examined LN metastasis from head and neck cancer by CT, mainly because contrast-enhanced $\mathrm{CT}$ is simple and can be performed at most institutions. In recent years, more imaging studies of residual tumours after RT have employed magnetic resonance imaging (MRI) and fluorodeoxyglucose-positron emission tomography (PET) $(12,13)$. However, CT is still the standard imaging modality because it requires a shorter scanning time and is less affected by motion artifacts compared with MRI, and CT is less expensive to perform than PET (14).
Table II. Univariate and multivariate analyses of the association between new changes after radiation therapy and histopathologically confirmed residual tumours.

\begin{tabular}{|c|c|c|c|c|}
\hline \multirow[t]{2}{*}{ New changes after RT } & \multirow{2}{*}{$\begin{array}{c}\begin{array}{c}\text { Univariate } \\
\text { analysis }\end{array} \\
p \text {-Value }\end{array}$} & \multicolumn{3}{|c|}{$\begin{array}{c}\text { Multivariate } \\
\text { analysis }\end{array}$} \\
\hline & & OR & $95 \% \mathrm{CI}$ & $p$-Value \\
\hline \multicolumn{5}{|l|}{ Reduction in the short axis } \\
\hline$<$ Median vs. $\geq$ median & 0.041 & 0.279 & $0.029-2.731$ & 0.273 \\
\hline \multicolumn{5}{|l|}{ Reduction in the long axis } \\
\hline$<$ Median $v s . \geq$ median & 0.041 & 0.710 & $0.087-5.803$ & 0.749 \\
\hline \multicolumn{5}{|c|}{ Obscuration of the margins } \\
\hline Yes $v s$. no & 0.019 & 14.125 & $1.761-113.296$ & 0.013 \\
\hline \multicolumn{5}{|l|}{ Internal necrosis } \\
\hline Yes vs. no & 0.382 & 2.304 & $0.431-12.318$ & 0.329 \\
\hline \multicolumn{5}{|l|}{ Calcification } \\
\hline Yes vs. no & 0.119 & 1.815 & $0.269-12.258$ & 0.541 \\
\hline \multicolumn{5}{|c|}{ Strong contrast enhancement } \\
\hline Yes $v s$. no & 0.123 & 6.638 & $0.794-55.466$ & 0.081 \\
\hline
\end{tabular}

CI: Confidence interval; RT: radiation therapy. Bold values indicate statistical significance.

In the present study, we examined the size of LNs both before and after RT. Some studies have suggested that LNs with suspected metastasis have a long axis $(>10 \mathrm{~mm}$ and the jugulodigastric LN $15 \mathrm{~mm}$ ) (9), or both short and long axes on pretreatment $\mathrm{CT}$ images were significantly greater for LNs with metastasis compared with those without metastasis (15). Other reports indicated that metastasis is more likely to be suspected in essentially spherical LNs (i.e. those with a long-to-short axis ratio of $<2)(9,15)$. In our patients, we detected no correlation between the LN size on CT pre-RT and the presence of residual tumours on ND, whereas both the short and long axes were significantly longer in LNs with residual tumours on the CT post-RT. These results suggest that $\mathrm{LN}$ size measurements after RT, rather than before, more accurately reflect the presence or absence of residual tumours on ND. These results have ramifications for patients who will receive $\mathrm{RT}$ in the future.

It is extremely difficult to determine whether post-RT tumours are actually residual tumours by imaging because of oedema and inflammation in the surrounding tissues. The sensitivity of CT for the detection of residual tumours after RT has been reported to range from $50 \%$ to $86 \%$ at primary sites $(13,14,16)$. There are few reports on the qualitative evaluation of LN metastasis after RT. Studies evaluating focal lucency, focal enhancement, and other focal abnormalities as indicators of residual tumours have reported positive predictive values for the presence and absence of focal heterogeneity of $36-46 \%$ and $29 \%$, respectively $(17,18)$. These qualitative evaluations were performed only with CT images taken before or after RT. 

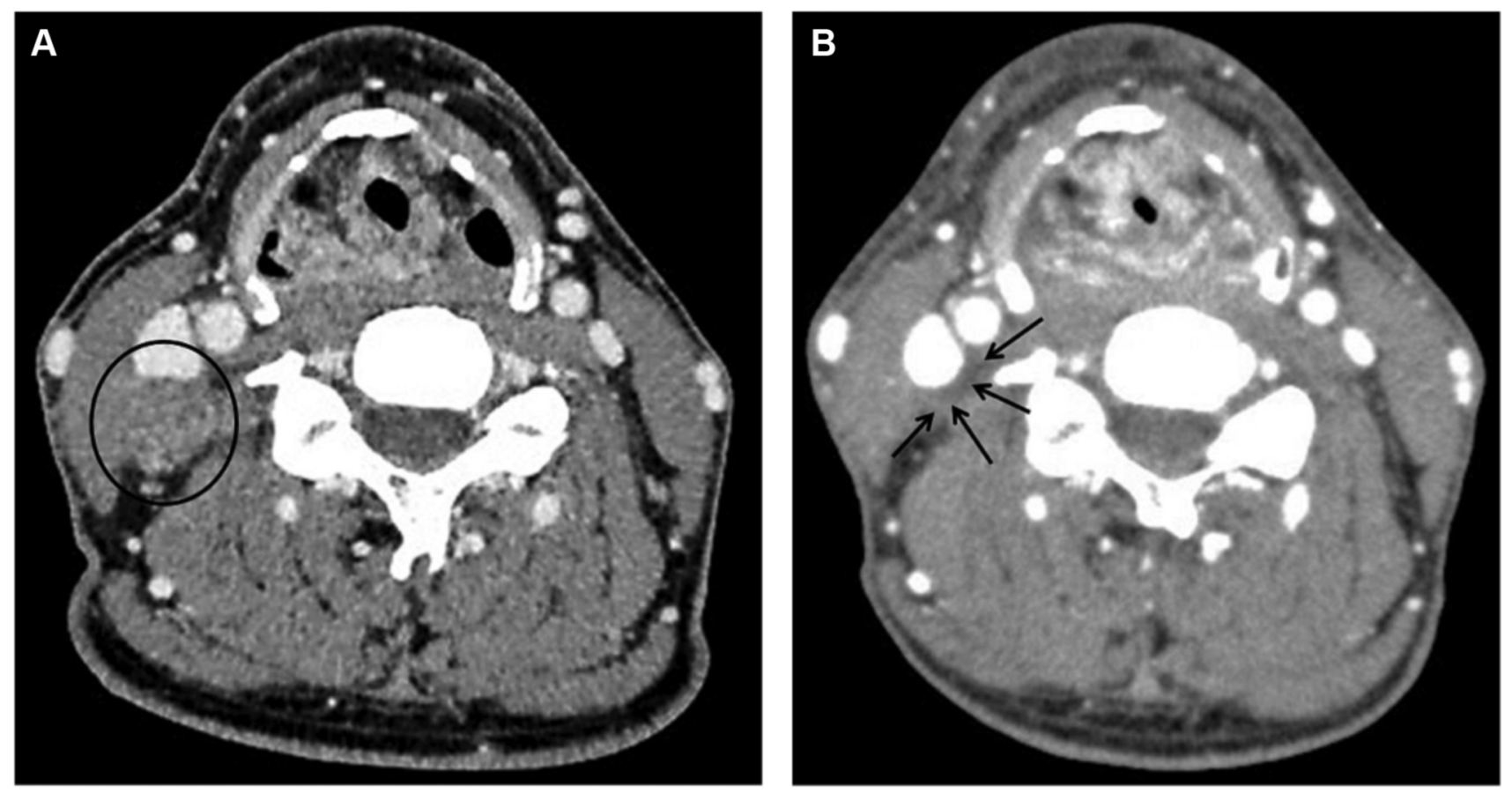

Figure 2. Histopathological residual tumours after salvage neck dissection. Representative contrast-enhanced computed tomographic images before (A) and after (B) radiotherapy, showing obscure margins (arrows) that were not present before radiotherapy.

The present study is the first qualitatively to evaluate new changes, such as obscuration of the margins, observed on CT images after RT but not before RT. In our patients, residual tumours were significantly more common in LNs with obscured margins after RT. Such obscuration may reflect new histopathological extracapsular spread of LN metastasis resistant to RT. While extracapsular spread of $\mathrm{LN}$ metastasis is a known factor for poor prognosis (19, 20), residual tumours after RT, like those observed in the present study, may also predict poor prognosis. The diagnosis of extracapsular spread is not always easy to make by CT, and its positive predictive value has been reported to range from $71 \%$ to $84 \%$ (21). We plan to continue accumulating cases and to conduct a histopathological study to determine the correlation between LNs without residual tumours and the presence of new obscuration of the margins and extracapsular spread after RT. As well as quantitative findings, such as the size, a new finding of obscured margins after post-RT CT images may improve the detection of residual tumour in patients with suspected residual or recurrent LN metastasis.

\section{Conflicts of Interest}

Drs. Ishibashi, Maebayashi, Nishimaki and Okada declare that they have no conflicts of interest in regard to this study.

\section{Authors' Contributions}

NI collected the patient data and treated the patients and was a major contributor to writing the article. HN reviewed the excised LNs. TM and MO treated the patients. All Authors read and approved the final article.

\section{Acknowledgements}

The Authors thank Anne M. O'Rourke, Ph.D., from Edanz Group (www.edanzediting.com/ac) for editing a draft of this article and helping to draft the abstract.

\section{References}

1 Robbins KT, Doweck I, Samant S and Vieira F: Effectiveness of superselective and selective neck dissection for advanced nodal metastases after chemoradiation. Arch Otolaryngol Head Neck Surg 131(11): 965-969, 2005. PMID: 16301367. DOI: 10.1001/ archotol.131.11.965

2 Simon C, Goepfert H, Rosenthal DI, Roberts D, El-Naggar A, Old M, Diaz EM Jr, Myers JN: Presence of malignant tumor cells in persistent neck disease after radiotherapy for advanced squamous cell carcinoma of the oropharynx is associated with poor survival. Eur Arch Otorhinolaryngol 263(4): 313-318, 2006. PMID: 16328403. DOI: 10.1007/s00405-005-1016-0

3 Adelstein DJ, Li Y, Adams GL, Wagner H Jr, Kish JA, Ensley JF, Schuller DE and Forastiere AA: An intergroup phase III comparison of standard radiation therapy and two schedules of 
concurrent chemoradiotherapy in patients with unresectable squamous cell head and neck cancer. J Clin Oncol 21(1): 92-98, 2003. PMID: 12506176. DOI: 10.1200/JCO.2003.01.008

4 Argiris A, Stenson KM, Brockstein BE, Mittal BB, Pelzer H, Kies MS, Jayaram P, Portugal L, Wenig BL, Rosen FR, Haraf DJ and Vokes EE: Neck dissection in the combined-modality therapy of patients with locoregionally advanced head and neck cancer. Head Neck 26(5): 447-455, 2004. PMID: 15122662. DOI: $10.1002 /$ hed.10394

5 Goguen LA, Posner MR, Tishler RB, Wirth LJ, Norris CM, Annino DJ, Sullivan CA, Li Y, Haddad RI. Examining the need for neck dissection in the era of chemoradiation therapy for advanced head and neck cancer. Arch Otolaryngol Head Neck Surg 132(5): 526-531, 2006. PMID: 16702569. DOI: 10.1001/ archotol.132.5.526

6 Corry J, Peters L, Fisher R, Macann A, Jackson M, McClure B and Rischin D: N2-N3 Neck nodal control without planned neck dissection for clinical/radiologic complete responders-results of Trans Tasman Radiation Oncology Group Study 98.02. Head Neck 30(6): 737-742, 2008. PMID: 18286488. DOI: 10.1002/ hed.20769

7 Nishimura G, Yabuki K, Hata M, Komatsu M, Taguchi T, Takahashi M, Shiono O, Sano D, Arai Y, Takahashi H, Chiba Y and Oridate N: Imaging strategy for response evaluation to chemoradiotherapy of the nodal disease in patients with head and neck squamous cell carcinoma. Int J Clin Oncol 21(4): 658667, 2016. PMID: 26710795. DOI: 10.1007/s10147-015-0936-y

8 Eisenhauer EA, Therasse P, Bogaerts J, Schwartz LH, Sargent D, Ford R, Dancey J, Arbuck S, Gwyther S, Mooney M, Rubinstein L, Shankar L, Dodd L, Kaplan R, Lacombe D and Verweij J: New response evaluation criteria in solid tumours: Revised RECIST guideline (version 1.1). Eur J Cancer 45(2): 228-247, 2009. DOI: 10.1016/j.ejca.2008.10.026

9 Gor DM, Langer JE and Loevner LA: Imaging of cervical lymph nodes in head and neck cancer: the basics. Radiol Clin North Am 44(1): 101-110, 2006. PMID: 16297684. DOI: 10.1016/ j.rcl.2005.08.006

10 Kaji AV, Mohuchy $\mathrm{T}$ and Swartz JD: Imaging of cervical lymphadenopathy. Semin Ultrasound CT MR 18(3): 220-249, 1997. PMID: 9253085. DOI: 10.1016/s0887-2171(97)90021-4

11 Hoang JK, Vanka J, Ludwig BJ and Glastonbury CM: Evaluation of cervical lymph nodes in head and neck cancer with CT and MRI: Tips, traps, and a systematic approach. Am J Roentgenol 200(1): W17-25, 2013. PMID: 23255768. DOI: 10.2214/AJR.12.8960

12 Kitagawa Y, Nishizawa S, Sano K, Ogasawara T, Nakamura M, Sadato N, Yoshida M and Yonekura Y: Prospective comparison of ${ }^{18}$ F-FDG PET with conventional imaging modalities (MRI, $\mathrm{CT}$, and ${ }^{67} \mathrm{Ga}$ scintigraphy) in assessment of combined intraarterial chemotherapy and radiotherapy for head and neck carcinoma. J Nucl Med 44(2): 198-206, 2003. PMID: 12571209.

13 Isles MG, McConkey C and Mehanna HM: A systematic review and meta-analysis of the role of positron-emission tomography in the follow-up of head and neck squamous cell carcinoma following radiotherapy or chemoradiotherapy. Clin Otolaryngol 33(3): 210-222, 2008. PMID: 18559026. DOI: 10.1111/j.17494486.2008.01688.x
14 Lell M, Baum U, Greess H, Nömayr A, Nkenke E, Koester M, Lenz $\mathrm{M}$ and Bautz W: Head and neck tumors: Imaging recurrent tumor and post-therapeutic changes with CT and MRI: Eur J Radiol 33(3): 239-247, 2000. PMID: 10699740. DOI: 10.1016/ s0720-048x(99)00120-5

15 Hung SH, Lin CY, Lee JY and Tseng H: Computed tomography image characteristics of metastatic lymph nodes in patients with squamous cell carcinoma of the head and neck. Auris Nasus Larynx 39(6): 606-610, 2012. PMID: 22326119. DOI: 10.1016/ j.anl.2011.10.017

16 Bongers V, Hobbelink MG, van Rijk PP and Hordijk GJ: Costeffectiveness of dual-head ${ }^{18} \mathrm{~F}$-fluorodeoxyglucose PET for the detection of recurrent laryngeal cancer. Cancer Biother Radiopharm 17(3): 303-306, 2002. PMID: 12136522. DOI: $10.1089 / 10849780260179260$

17 Liauw SL, Mancuso AA, Amdur RJ, Morris CG, Villaret DB, Werning JW and Mendenhall WM: Postradiotherapy neck dissection for lymph node-positive head and neck cancer: The use of computed tomography to manage the neck. J Clin Oncol 24(9): 1421-1427, 2006. PMID: 16549836. DOI: 10.1200/ JCO.2005.04.6052

18 Clavel S, Charron MP, Bélair M, Delouya G, Fortin B, Després P, Soulières D, Filion E, Guertin L and Nguyen-Tan PF: The role of computed tomography in the management of the neck after chemoradiotherapy in patients with head-and-neck cancer. Int J Radiat Oncol Biol Phys 82(2): 567-573, 2012. PMID: 21310545. DOI: 10.1016/j.ijrobp.2010.11.066

19 Brasilino de Carvalho M: Quantitative analysis of the extent of extracapsular invasion and its prognostic significance: a prospective study of 170 cases of carcinoma of the larynx and hypopharynx. Head Neck 20(1): 16-21, 1998. PMID: 9464947. DOI: 10.1002/(sici) 1097-0347(199801)20:1<16::aid-hed3>3.0.co;2-6

20 Johnson JT, Barnes EL, Myers EN, Schramm VL Jr, Borochovitz D and Sigler BA: The extracapsular spread of tumors in cervical node metastasis. Arch Otolaryngol 107(12): 725-729, 1981. PMID: 7316852. DOI: 10.1001/archotol.1981.00790480001001

21 Chai RL, Rath TJ, Johnson JT, Ferris RL, Kubicek GJ, Duvvuri $\mathrm{U}$ and Branstetter BF $4^{\text {th: }}$ : Accuracy of computed tomography in the prediction of extracapsular spread of lymph node metastases in squamous cell carcinoma of the head and neck. JAMA Otolaryngol Head Neck Surg 139(11): 1187-1194, 2013. PMID: 24076619. DOI: $10.1001 /$ jamaoto.2013.4491
Received April 17, 2020

Revised May 1, 2020

Accepted May 6, 2020 